\title{
A comparative study on the electronic and optical properties of $\mathrm{Sb}_{2} \mathrm{Se}_{3}$ thin film
}

\author{
(C) M. Kamruzzaman ${ }^{1}$, Chaoping Liü ${ }^{2}$, A.K.M. Farid UI Islam³ ${ }^{3}$ J.A. Zapien ${ }^{1}$ \\ ${ }^{1}$ Department of Physics and Materials Science and Center of Super-Diamond and Advanced Films (COSDAF), \\ City University of Hong Kong, \\ Hong Kong SAR, P.R. China \\ ${ }^{2}$ Department of Physics and Materials Science, City University of Hong Kong, \\ Hong Kong SAR, P.R. China \\ ${ }^{3}$ Department of Computer Science and Engineering, Begum Rokeya University, Rangpur, \\ Rangpur-5400, Bangladesh \\ E-mail: kzaman.phy17@gmail.com, liuchaoping7281@hotmail.com, farid_ru@yahoo.com, apjazs@cityu.edu.hk
}

(Received 2.09.2016. Received after revision 27.04.2017)

\begin{abstract}
The thin film of $\mathrm{Sb}_{2} \mathrm{Se}_{3}$ was deposited by thermal evaporation method and the film was annealed in $N_{2}$ flow in a three zone furnace at a temperature of $290^{\circ} \mathrm{C}$ for $30 \mathrm{~min}$. The structural properties were characterized by scanning electron microscopy (SEM), transmission electron microscopy (TEM), $X$-ray diffraction (XRD) and Raman spectroscopy, respectively. It is seen that the as-deposited film is amorphous and the annealed film is polycrystalline in nature. The surface of $\mathrm{Sb}_{2} \mathrm{Se}_{3}$ film is oxidized with a thickness of $1.15 \mathrm{~nm}$ investigated by $X$-ray photolecetron spectroscopy (XPS) measurement. Spectroscopic ellipsometry (SE) and UV-vis spectroscopy measurements were carried out to study the optical properties of $\mathrm{Sb}_{2} \mathrm{Se}_{3}$ film. In addition, the first principles calculations were applied to study the electronic and optical properties of $\mathrm{Sb}_{2} \mathrm{Se}_{3}$. From the theoretical calculation it is seen that $\mathrm{Sb}_{2} \mathrm{Se}_{3}$ is intrinsically an indirect band gap semiconductor. Importantly, the experimental band gap is in good agreement with the theoretical band gap. Furthermore, the experimental values of $n, k, \varepsilon_{1}$, and $\varepsilon_{2}$ are much closer to the theoretical results. However, the obtained large dielectric constants and refractive index values suggest that exciton binding energy in $\mathrm{Sb}_{2} \mathrm{Se}_{3}$ should be relatively small and an antireflective coating is recommended to enhance the light absorption of $\mathrm{Sb}_{2} \mathrm{Se}_{3}$ for thin film solar cells application.
\end{abstract}

DOI: $10.21883 /$ FTP.2017.12.45184.8396

\section{Introduction}

The group V-VI compound semiconductors are useful for their numerous applications as electronic, optoelectronic, thermoelectric photoconducting target, television camera and infrared spectroscopy $[1,2]$. Antimony selenide $\left(\mathrm{Sb}_{2} \mathrm{Se}_{3}\right)$ is a binary compound semiconductor belongs to the group $\mathrm{V}-\mathrm{VI}$ with a band gap of $1.1-1.2 \mathrm{eV}[1,2]$. It was first introduced in 1950s [3] in the natural mineral antimonselite [4]. It is an orthorhombic crystal with the space group of Pnma 62 [1-2]. It exhibits good thermoelectric and photovoltaic properties which allow possible applications for thermoelectric, thermophotovoltaic [5-8], solar cells [9] and so on. From the last decade intensive research has been focused on $\mathrm{Sb}_{2} \mathrm{Se}_{3}$ as an alternative promising light absorber materials for organic-inorganic hybrid solar cells fabrication $[5,10]$ due to its narrow band gap, low cost, nontoxic, comparatively earth abundant as well as amorphous phase crystallizes readily with a slight increase in temperature [11]. The melting point of $\mathrm{Sb}_{2} \mathrm{Se}_{3}$ is $608^{\circ} \mathrm{C}$ [12] and the crystallization temperature $197^{\circ} \mathrm{C}[13], 183-198^{\circ} \mathrm{C}$ [14] as well as the glass transition temperature $169^{\circ} \mathrm{C}$ [14]. The optimized crystalline temperature $290-300^{\circ} \mathrm{C}$ under $30 \mathrm{~min}$ annealing condition $[12,15,16]$. It is also reported that the device performance is better for the film deposited at substrate temperature of $300^{\circ} \mathrm{C}$ rather than $350^{\circ} \mathrm{C}[12,15]$. In addition, the TGA analysis showed that the weight loss started at approximately $423^{\circ} \mathrm{C}$, then increased sharply after temperature $608^{\circ} \mathrm{C}$ [12]. From this literature review, it is clear that the thermal stability of amorphous $\mathrm{Sb}_{2} \mathrm{Se}_{3}$ film is at $197^{\circ} \mathrm{C}$ and the crystallization stability is at $189-423^{\circ} \mathrm{C}$ [12]. The absorption coefficient is very high $(\alpha)>10^{5} \mathrm{~cm}^{-1}$ in the short wavelength range (close to the absorption onset) to be considered an alternative absorber instead of conventional cadmium telluride $(\mathrm{CdTe})$ and copper indium gallium selenide (CIGS) solar cells $[1,2]$. Although, CdTe and CIGS solar cells have reported very impressive photovoltaic efficiency (PCE) 20.4 and 20.8\%, however, the toxicity of $\mathrm{Cd}$, high price and scarcity of In, $\mathrm{Te}$ and $\mathrm{Ga}$ can be impeded in the large scale production and applications [1]. An alternative promising absorber of copper zinc tin sulfoselenide (CZTSSe) has also been extensively investigated for solar cells performance through using toxic hydrazine-based solution process and having reported efficiency $12.6 \%$ [17], but it has a wider range of possible defect compare to binary or ternary compounds. Very recently, the state of the art hybrid class perovskite solar cells are the most attractive research field because of its excellent certified efficiency $22.1 \%$ [18] and simple fabrication process. However, the poor long term stability and the toxicity of $\mathrm{Pb}$ issues cast doubt on its further commercialization $[2,19]$. On the other hand, the performance of polymer solar cells degrades in atmospheric conditions [20]. Thus, $\mathrm{Sb}_{2} \mathrm{Se}_{3}$ has been attracted much attention because of the aforementioned criteria and versatile technological applications $[10,21-25]$. In particular, $\mathrm{Sb}_{2} \mathrm{~S}_{3}$ is used as an effective absorber layer in organic-inorganic hybrid solar cells [10] which are stable upon exposure to ambient 
air [25]. Although, $\mathrm{Sb}_{2} \mathrm{Se}_{3}$ is used in various fields, the lack of proper knowledge regarding its electronic structure and optical properties sometimes leads to contradictory interpretations of the experimental data found in literature [26]. Regarding the direct/indirect band gap nature a few contradictory reports are available in literature: 1.0 to $1.82 \mathrm{eV}$ for single crystals [27-31], for thin films direct (1.5-2.14) eV [32-34], indirect transitions $(1-1.2) \mathrm{eV}[35-$ 39 ], and the theoretical indirect band gap energy of $1.21 \mathrm{eV}$ using density functional theory (DFT) within the obtained gradient approximation (GGA) with GW corrections [26], as well as $0.99 \mathrm{eV}$ (indirect) $-1.07 \mathrm{eV}$ (direct) obtained using DFT with LDA [40].

Various methods have been used to deposit $\mathrm{Sb}_{2} \mathrm{Se}_{3}$ thin film such as thermal evaporation $[12,15,41]$, spin coating [42], electrodeposition [43], solvothermal [44] and hydrothermal method [39] etc. To the best of our knowledge, no comparative report is available in literature regarding the theoretical and experimental study. To this point of view, we deposit $\mathrm{Sb}_{2} \mathrm{Se}_{3}$ thin film by thermal evaporation method, and investigated structural and optical properties. The first principles calculations were performed on the electronic structure and fundamental optical properties to compare with the experimental results.

\section{Methodology}

Prior to deposit $\mathrm{Sb}_{2} \mathrm{Se}_{3}$ layer, p-type $\mathrm{Si}\langle 100\rangle$ $\left(1.5 \times 1.5 \mathrm{~cm}^{2}\right)$ single crystal with resistivity of $10 \Omega \cdot \mathrm{cm}^{-1}$ and glass substrates were subsequently cleaned in Decon 90 , acetone, ethanol and deionized water with the assistance of ultrasonic bath each for 15 minutes then dried in nitrogen gas flow and finally cleaned in UV-Ozon cleaner chamber for $10 \mathrm{~min}$. $\mathrm{A} \sim 258 \mathrm{~nm}$ thick layer of $\mathrm{Sb}_{2} \mathrm{Se}_{3}$ was deposited on the substrates ( $p$-Si and glass) by the thermal evaporation method at a base pressure of $2.4 \cdot 10^{-6} \mathrm{mbar}$ and the deposition rate was $0.06 \mathrm{~nm} / \mathrm{s}$. The $\mathrm{Sb}_{2} \mathrm{Se}_{3}$ thin film was deposited onto $p$-type $\mathrm{Si}$ substrate (for optical properties calculations using spectroscopy ellipsometry and Raman characterization) and glass substrate for surface morphology, XRD, XPS studies. The deposited $\mathrm{Sb}_{2} \mathrm{Se}_{3}$ layer was annealed in a $N_{2}$ flow three zones furnace at a temperature of $290^{\circ} \mathrm{C}$ for $30 \mathrm{~min}$. The surface morphology and crosssection of the film were characterized by field emission scanning electron microscopy (FE-SEM) (Philips XL30 FEG). Transmission electron microscopy (TEM) images were collected by a high resolution TEM with $200 \mathrm{keV}$ (Philips FEG TEM CM200). $X$-ray diffraction (Rikagu Smart Lab diffraction) data were taken in the range of 10 to $60^{\circ}$ with a step width of $0.02^{\circ}$. UV-vis reading was collected at room temperature (RT) in the wavelength range 370 to $1100 \mathrm{~nm}$ (Parkin Elmer lambda 2S) and spectroscopic ellipsometry (SE) measurement was carried out by J.-A. Woolson Jewel (M-2000). In addition, the crystallinity was investigated by Renishaw-Invia micro-Raman spectroscope (excitation wavelength $514 \mathrm{~nm}$ ) spectroscopy. $X$-ray photoelectron spectroscopy (XPS: PHI 5802) readings were taken to examine chemical states and the oxidized effect.
The first principles calculations were applied to study the electronic and optical properties of $\mathrm{Sb}_{2} \mathrm{Se}_{3}$ in the framework of DFT with generalized gradient approximation (GGA) as implemented in the CASTEP code [45]. The basis set of the valence electronic states were taken as: $5 s^{2} 5 p^{3}$ and $4 s^{2} 4 p^{4}$ for $\mathrm{Sb}$ and $\mathrm{Se}$, respectively. The cutoff energy is taken $500 \mathrm{eV}$ and $3 \times 9 \times 3$ Monkhorstpack grid for the sampling of the Brillouin zone. The space group of $\mathrm{Sb}_{2} \mathrm{Se}_{3}$ is Pnma (62). The atomic positions considered as, $\mathrm{Sb}_{1}(0.5304,0.25,0.1721) ; \mathrm{Sb}_{2}$ (0.6475, 0.75, 0.4604); $\mathrm{Se}_{1}(0.6289,0.75,0.0553) ; \mathrm{Se}_{2}$ $(0.7141,0.25,0.3051)$, and $\mathrm{Se}_{3}(0.4464,0.75,0.3713)$. Geometrical optimization is conducted using the convergence of thresholds of $5 \cdot 10^{-6} \mathrm{eV} /$ atom for the total energy. The maximum force, maximum stress and maximum displacement were selected as $0.01 \mathrm{eV} \cdot \AA^{-1}$, $0.02 \mathrm{GPa}$ and $5 \cdot 10^{-4} \AA$. We undertake 0.5 Gaussian smearing for all calculations to smear out the Fermi level so that the $k$-points will be more effective on the Fermi surface.

\section{Results and discussion}

\subsection{Surface morphology}

Fig. 1, $a, b$ show the SEM images of the as-deposited and annealed films. The as-deposited film shows a smooth surface with undefined grain size whereas large grain size developed in the annealed film without any void implies that the as-deposited film is an unstable phase that transferred from amorphous phase to crystalline phase under heat treatment. To check the crystallinity of the annealed film a low resolution (LRTEM, Fig. 1,c), high resolution (HRTEM, inset top Fig. 1,d) and selective area electron diffraction (SAED, Inset below Fig. 1,e) TEM images are depicted. It can be seen from LRTEM that the grain size $>20.0 \mathrm{~nm}$ which is consisted with XRD result (Table 1). SAED and HRTEM images show the crystalline nature of the annealed film. Fig. 1, $a$ (inset) shows the EDX spectrum of $\mathrm{Sb}_{2} \mathrm{Se}_{3}$ film.

In the spectrum two peaks for $\mathrm{Sb}$ and $\mathrm{Se}$ elements are clearly observed where an $\mathrm{O}$ (oxygen) peak is overlapped with $\mathrm{Sb}$ indicate that $\mathrm{Sb}_{2} \mathrm{Se}_{3}$ is oxidized and its secondary chemical state is $\mathrm{Sb}_{2} \mathrm{O}_{3}$.

\section{2. $X$-ray diffraction (XRD)}

Fig. 2, a shows XRD pattern of the as-deposited and annealed films of $\mathrm{Sb}_{2} \mathrm{Se}_{3}$. No characteristic sharp peaks are observed except a broad hump in the low diffraction angle that indicates the glassy nature of the as-deposited film. In contrast, a few diffraction peaks are observed in the annealed film. These peaks were indexed with the JCPDS card 15-0861 of $\mathrm{Sb}_{2} \mathrm{Se}_{3}$ for the orthorhombic structure that correspond to (110), (020), (120), (310), (230), (221), (301), (240), (321), (141), (250), (431), and (061) planes, respectively. In addition, an extra peak is found at $\sim 46.95^{\circ}$ 

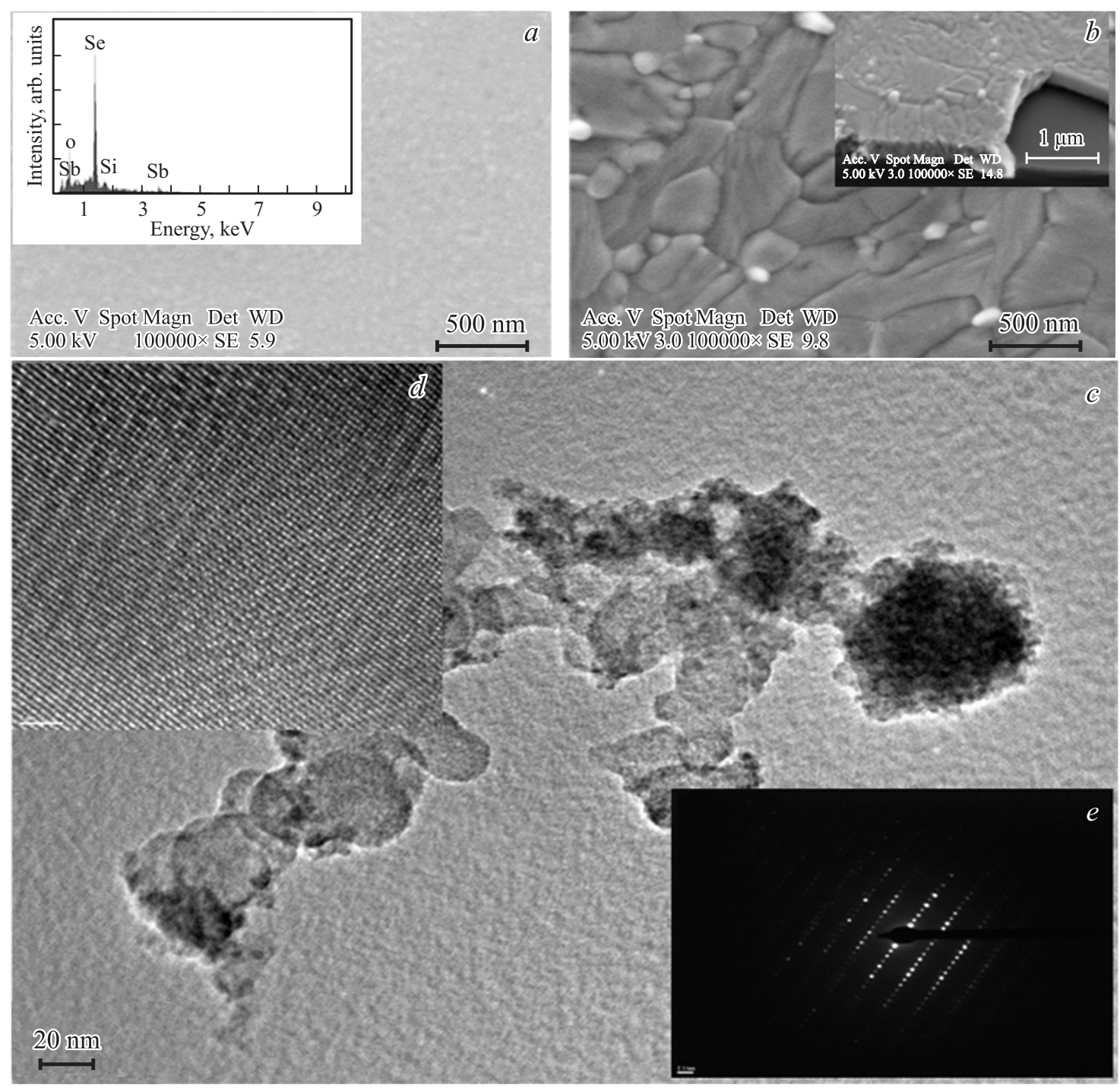

Figure 1. SEM images for top and side view $(a)$ as-deposited, and ED X (inset), $(b)$ annealed and cross-section (inset). TEM images for $(c)$ low resolution, $(d)$ high resolution (inset, top) and $(e)$ selected area electron diffraction (inset, below).
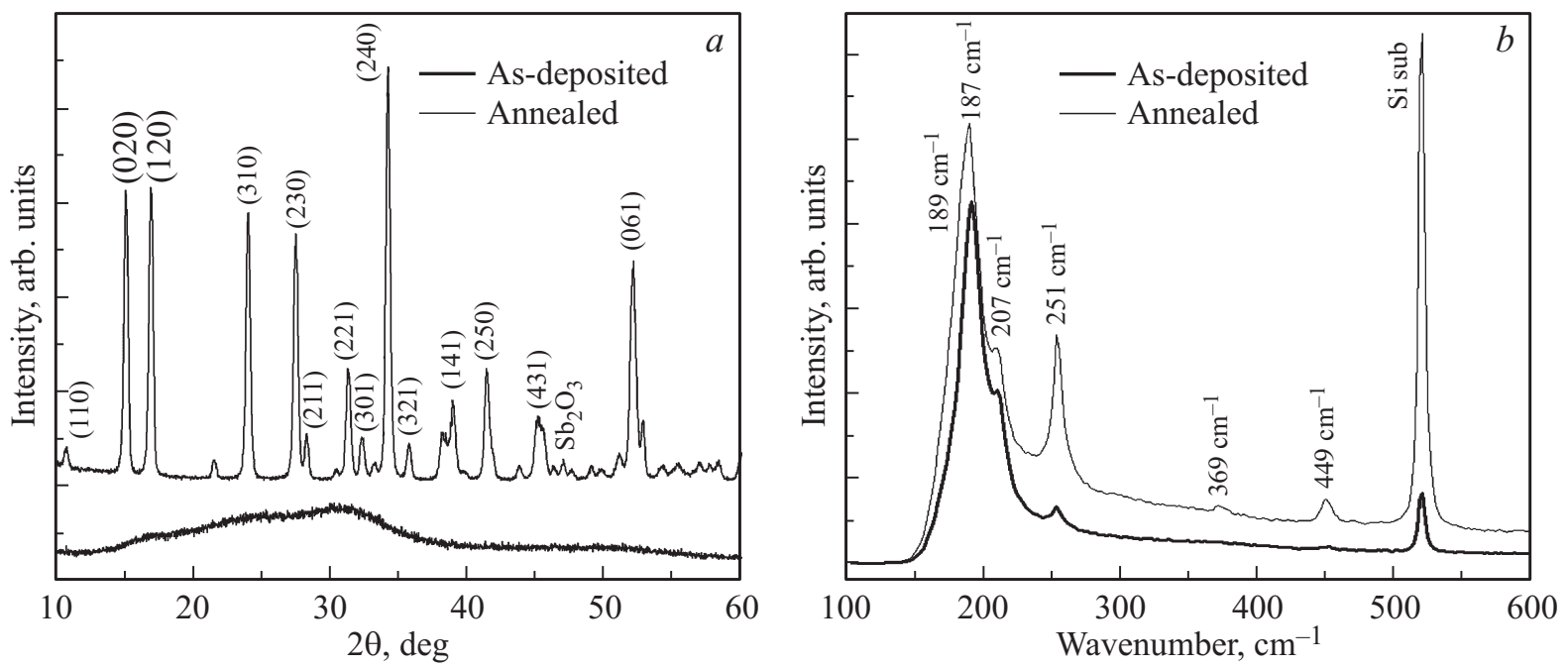

Figure 2. $a-X$-ray diffraction patterns and $b-$ Raman spectra of $\mathrm{Sb}_{2} \mathrm{Se}_{3}$. 

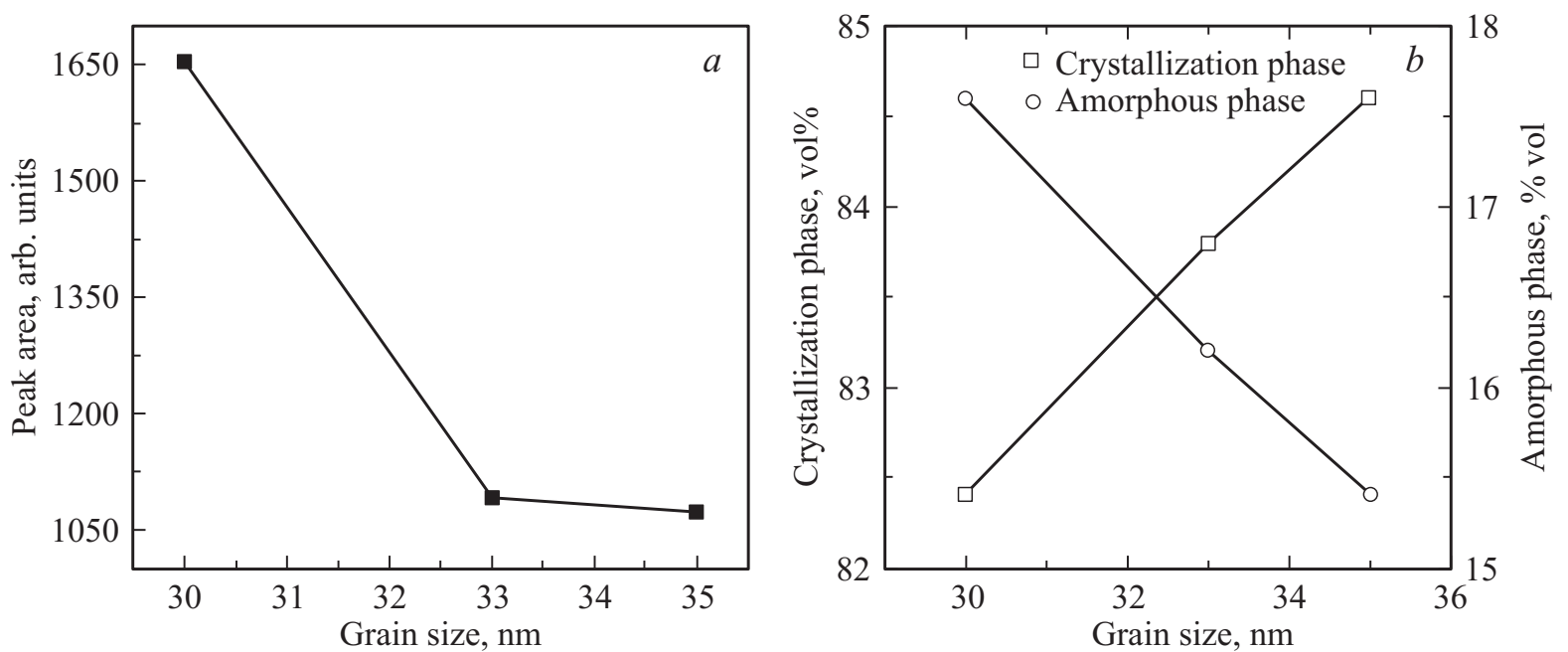

Figure 3. $a$ - peak area of crystallization phase and $b$ - amorphous and crystalline phasesvolume fraction of the annealed film $\mathrm{Sb}_{2} \mathrm{Se}_{3}$.

seems to be oxide phase of $\mathrm{Sb}_{2} \mathrm{O}_{3}$. The lattice parameters and the grain size were calculated using equations (1) and Scherrer formula (2), respectively

$$
\begin{gathered}
\frac{1}{d^{2}}=\frac{h^{2}}{a^{2}}+\frac{k^{2}}{b^{2}}+\frac{l^{2}}{c^{2}}, \\
L_{s}=\frac{0.9 \lambda}{\beta \cos \theta} .
\end{gathered}
$$

The estimated lattice constants were found to be, $a=1.172 \mathrm{~nm}, b=1.171 \mathrm{~nm}$, and $c=0.396 \mathrm{~nm}$ (Table 1$)$. The obtained lattice parameters are well agreed with the reported values [46], however they are slightly deviated from the standard values $a=1.163 \mathrm{~nm}, b=1.178 \mathrm{~nm}$, and $c=0.3985 \mathrm{~nm}$. Average grain size of the annealed film was obtained $33.0 \mathrm{~nm}$ (Table 1) is consistent with the TEM result.

The XRD crystallization peak area was calculated based on the selected peak area devoid of the background area which was considered to be amorphous phase $X$-ray scattering [47]. The base line was selected about 1.5 degrees on either side of the (020), (240) and (061) peaks to calculate the background average intensity. This was to minimize any angular dependence in the background Fig. 2, a. Moreover, the limits were considered to be near to the selected peak and not belonging to the crystalline peak profile. The area of main peak was calculated by using the following formula [47],

$$
\begin{aligned}
\text { Peak Area }=0.5 \times & \text { FWHM } \times(\text { peak } \\
& \text { intensity-background intensity }) .
\end{aligned}
$$

The grain size and the obtained peak area for (020), (240) and (061) planes are shown in Fig. 3,a. From Fig. 3, $a$, it is obvious that the peak area reduces as the grain size increase. Using the calculated crystalline size, the crystalline phase percentage volume (for orthorhombic grain size) was calculated and the obtained results are shown
Table 1. Lattice constants, grain size and volume of $\mathrm{Sb}_{2} \mathrm{Se}_{3}$ thin film

\begin{tabular}{c|c|c|c|c}
\hline \multicolumn{2}{c|}{ Lattice constants, $\AA$} & \multirow{2}{*}{ Grain Size, $\AA$} & \multirow{2}{*}{ Volume, $\AA^{3}$} \\
\hline$a$ & $b$ & $c$ & & \\
\hline 11.73 & 11.73 & 3.96 & 230.0 & 544.12
\end{tabular}

in Fig. 3,b. Using the same method, the percentage of the amorphous phase (grain boundary volume, and the boundary width was assumed to be $1.5 \mathrm{~nm}$ for orthorhombic structure) percentage volume is also shown in the same Fig. 3, $b$. From the Fig. 3, $b$, a strong correlation is observed that, as the peak area is increased the amorphous phase volume increased and the crystallization phase volume decreased.

\subsection{Raman spectroscopy}

Raman spectra data were collected in the wavenumber range $100-600 \mathrm{~cm}^{-1}$ of the as-deposited and annealed films of $\mathrm{Sb}_{2} \mathrm{Se}_{3}$ (Fig. 2,b). There are three bands in the as-deposited film while five bands in the annealed film. The bands centered at 189 and $251 \mathrm{~cm}^{-1}$ corresponding to the heteropolar $\mathrm{Sb}-\mathrm{Se}$ and nonpolar $\mathrm{Sb}-\mathrm{Sb}$ vibrations, respectively $[1,48]$. The broad band located at $189 \mathrm{~cm}^{-1}$ is the finger print of $\mathrm{Sb}_{2} \mathrm{Se}_{3}$. However, the peak position of $189 \mathrm{~cm}^{-1}$ is shifted $\left(\sim 2 \mathrm{~cm}^{-1}\right)$ at lower wavenumber region attributed to the decreasing/removing internal stress or defects as a result of annealing. A low intensity peak centered at $207 \mathrm{~cm}^{-1}$ is also the characteristic peak of $\mathrm{Sb}_{2} \mathrm{Se}_{3}$ [49]. Apart from that, two extra peaks are seen in the annealed spectrum centered at 369 and $449 \mathrm{~cm}^{-1}$ belong to the secondary unintensional phase of $\mathrm{Sb}_{2} \mathrm{O}_{3}$ [50]. Appearing of these peaks signifies that the $\mathrm{Sb}_{2} \mathrm{Se}_{3}$ is highly sensitive to oxygen. It should be noted that the position 

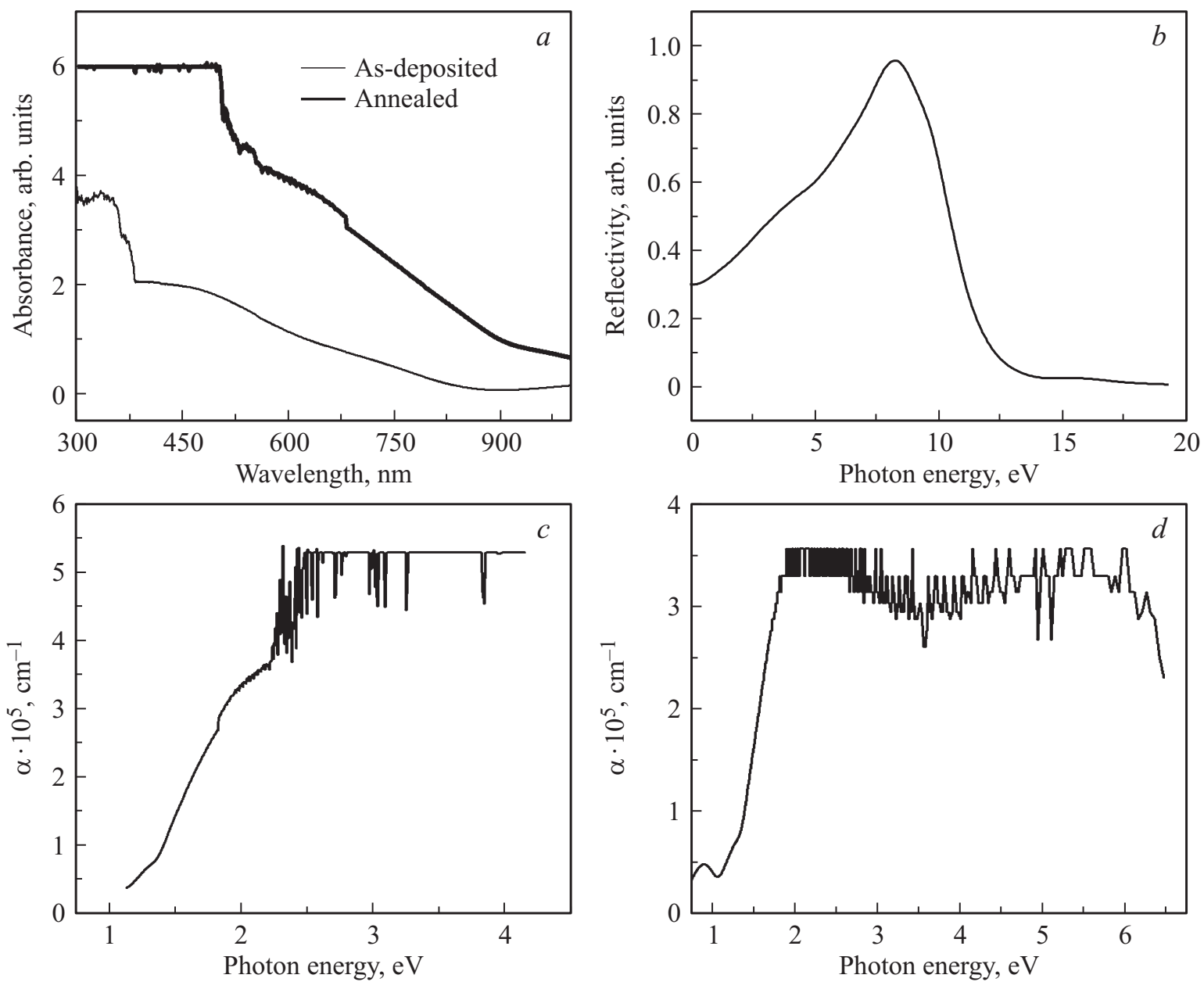

Figure 4. Absorbance of the as-deposited and annealed films $(a)$, theoretical reflectivity $(b)$, absorption coefficients obtained from UV-vis $(c)$ and SE $(d)$, respectively.

and the profile of Raman peaks depend on several factors such as crystallization, structural disorder, crystal defects and residual stress etc.

\subsection{Optical properties}

It is still a controversial regarding the optical transition type of $\mathrm{Sb}_{2} \mathrm{Se}_{3}$. To better understand the performance of $\mathrm{Sb}_{2} \mathrm{Se}_{3}$ based optoelectronic devices a comparative systematic optical properties study is crucial. To this point of view, a powerful spectroscopic ellipsometry (SE) measurement was taken for $\mathrm{Sb}_{2} \mathrm{Se}_{3}$ thin film. The optical constants and the thickness of the thin film were found out after a good fitting of the experimental data to the data generated by the optical model [51]. The measurements and the fitting process are described elsewhere [52]. The band gap, refractive index, extinction coefficient and dielectric constant were calculated after a good fitting. The obtained results are shown in Figs. 4, $d ; 5, a-d, g$ and Table 2, respectively. From Fig. $4, a$ it is seen that the absorption is increased significantly after annealing indicates the improvement of the crystallinity nature of the film. The reflectivity of $\mathrm{Sb}_{2} \mathrm{Se}_{3}$ is very high (Fig. 4, b, theoretical calculation). It is interesting that the absorption coefficient $(\alpha)$ of $\mathrm{Sb}_{2} \mathrm{Se}_{3}$ is greater than $10^{5} \mathrm{~cm}^{-1}$ obtained from UV-vis and SE measurements (Fig. 4, $c$ and $d$ ).

Table 2. Optical parameters values obtained from UV-vis, SE and theoretical calculations

\begin{tabular}{c|c|c|c|c|c|c|c|c|c|c}
\hline \multirow{2}{*}{ Obtained from } & \multicolumn{2}{|c|}{ Band gap, $\mathrm{eV}$} & \multicolumn{2}{c|}{$n_{\max }$ at photon energy } & \multicolumn{2}{c|}{$k_{\max }$ at photon energy } & \multicolumn{4}{|c}{ Dielectric constants $\left(\varepsilon_{1}, \varepsilon_{2}\right)$} \\
\cline { 2 - 10 } & Direct & Indirect & $n$ & $\mathrm{eV}$ & $k$ & $\mathrm{eV}$ & $\varepsilon_{\text {real }}$ & $\mathrm{eV}$ & $\varepsilon_{\text {ima }}$ & $\mathrm{eV}$ \\
\hline UV-vis & 1.6 & 1.0 & - & - & - & - & - & - & - & - \\
SE & 1.65 & 1.5 & 5.50 & 1.86 & 3.11 & 3.12 & 23.76 & 1.49 & 22.81 & 2.78 \\
Theory & - & $\sim 0.94$ & 3.99 & 1.93 & 2.88 & 3.67 & 14.97 & 1.63 & 16.83 & 2.91
\end{tabular}



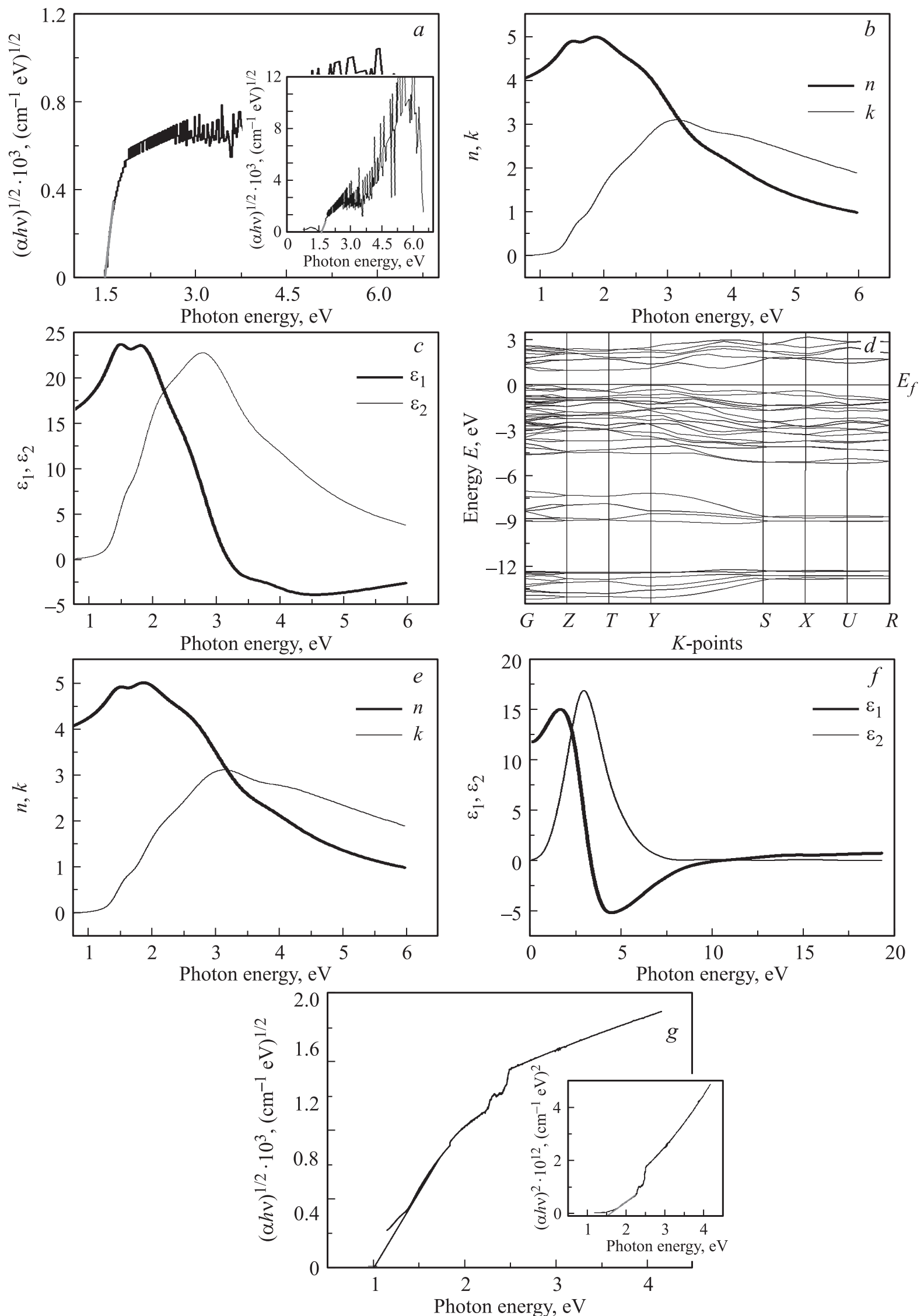

Figure 5. Band gap obtained from SE $(a)$ indirect, direct (inset), $(b) n, k$ and $(c) \varepsilon_{1}, \varepsilon_{2}$. Theoretical calculations: $(d)$ band structure, $(e) n, k$ and $(f) \varepsilon_{1}, \varepsilon_{2}$. Band gap obtained from UV-vis spectroscopy $(g)$ indirect, direct (inset). 

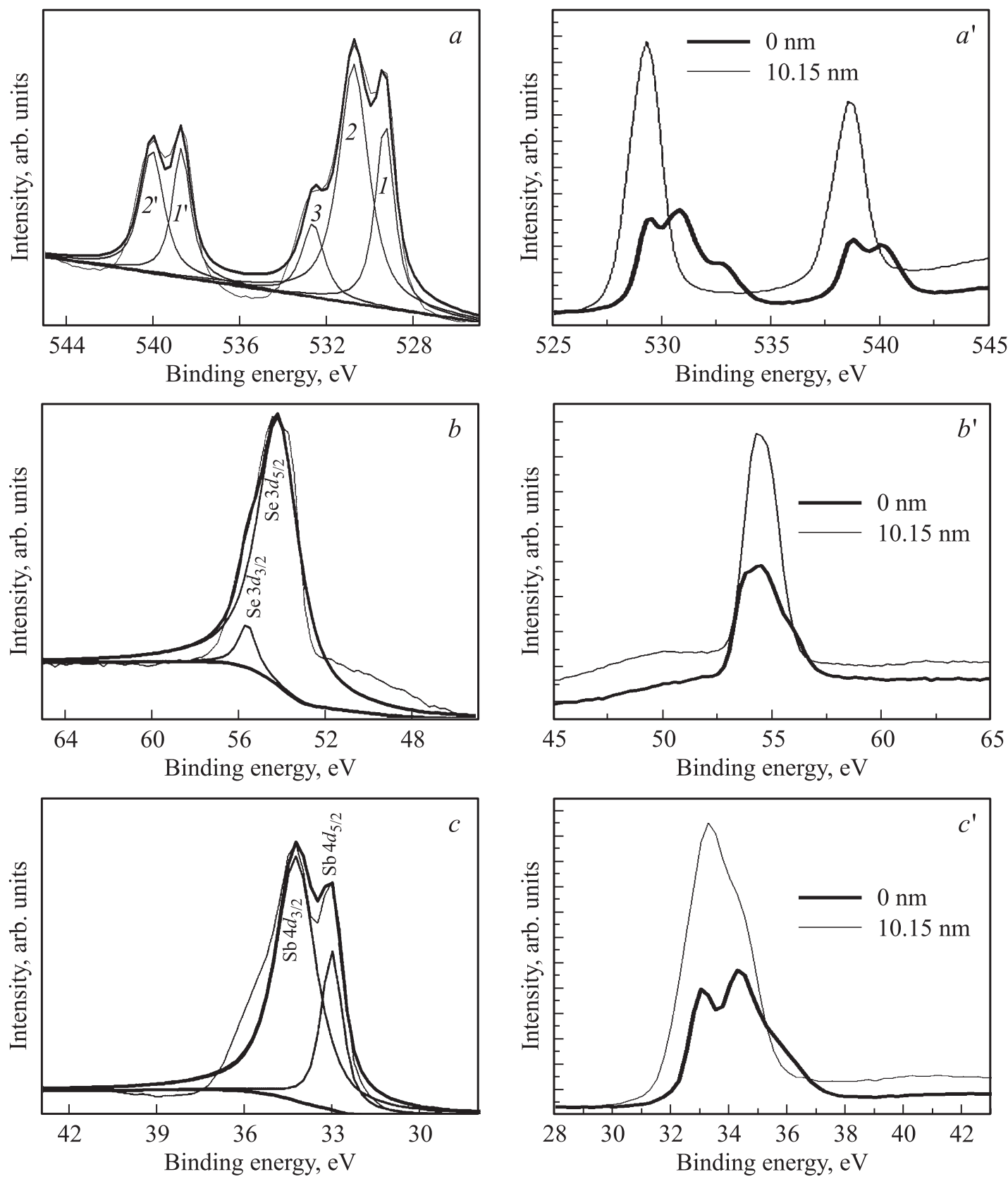

Figure 6. (a) XPS spectra of $\mathrm{Sb}_{2} \mathrm{Se}_{3}$ : the lines correspond to experimental data and fitted spectrum, respectively $(a) 1\left(\mathrm{Sb}_{2} \mathrm{Se}_{3}\right): \mathrm{Sb}_{3} d_{5 / 2}$, $1^{\prime}\left(\mathrm{Sb}_{2} \mathrm{Se}_{3}\right): \mathrm{Sb}_{3} d_{3 / 2}, 2\left(\mathrm{Sb}_{2} \mathrm{O}_{3}\right): \mathrm{Sb} 3 d_{5 / 2}, 2^{\prime}\left(\mathrm{Sb}_{2} \mathrm{O}_{3}\right): \mathrm{Sb} 3 d_{3 / 2}, 3: \mathrm{O} 1 s,(b) \mathrm{Se} 3 d$ and $(c) \mathrm{Sb} 4 d$. Depth profiling of $\mathrm{Sb}_{2} \mathrm{Se}_{3}$ up to $10.15 \mathrm{~nm}$ for $\left(a^{\prime}\right) \mathrm{Sb} 3 d,\left(b^{\prime}\right) \mathrm{Se} 3 d$ and $\left(c^{\prime}\right) \mathrm{Sb} 4 d$, respectively.

The optical band gap energy is determined from $(\alpha h \vartheta)^{2} v s . \quad h v$ (direct band gap) and $(\alpha h \vartheta)^{1 / 2} v s . h v$ curves (indirect band gap) by drawing an extrapolation of the data point to the photon energy axis where $(\alpha h \vartheta)^{2}$ or $(\alpha h \vartheta)^{1 / 2}=0$. The direct and indirect band gap energy is found to be $1.65 \mathrm{eV}$ and $1.5 \mathrm{eV}$ (Fig. 5, $a$, from SE measurement). The band gap energy was also determined from UV-vis reading and the value obtained to be $1.6 \mathrm{eV}$ (direct) and $1.0 \mathrm{eV}$ (indirect) (inset Fig. 5,g and Fig. 5,g), respectively. Fig. 5, $d$ shows the theoretical calculations of the band dispersion of $\mathrm{Sb}_{2} \mathrm{Se}_{3}$ along the Brillouin zone path $G-Z-T-Y-S-X-U-R$. From this band structure it is clear that $\mathrm{Sb}_{2} \mathrm{Se}_{3}$ form an indirect transition band gap nature and the band gap to be $\sim 0.94 \mathrm{eV}$. From Table 2 it is clear that the obtained direct band gap is in good agreement with SE and UV-vis as well as reported values [26,33-36] while indirect band gap is consistent with UV-vis, theoretical and the reported values $[35,36,38]$. However, the theoretical value is a little bit smaller than the experimental values due to exchange correlation [53] and the formation of nanocrystalline after annealing could be introduced quantum size effect. The calculated real re- 
fractive index, extinction coefficient and dielectric constants are shown in Figs. 5, $b$ and $c$ (from SE) while theoretical values in Figs. 5, $d$ and $e$. From the graphs (Fig. 4) and Table 2 it is apparent that the experimeantal results are much closer to the theoretical calculations. Importantly, the obtained dielectric constant is larger than the copper indium gallium diselenide (CIGS) [54]. The large value of dielectric constant of $\mathrm{Sb}_{2} \mathrm{Se}_{3}$ suggests that smaller exciton binding energy and possibly transient separation of electrons and holes pair upon photons irradiation and the large value of $\varepsilon^{\prime \prime}$ related to the dielectric loss is favorable for light harvesting in $\mathrm{Sb}_{2} \mathrm{Se}_{3}$ film. Furthermore, the real part of the dielectric constant is distinctively a negative value from 3.29 to 10.62 (Fig. 5,e). The negative value of the dielectric constant implies that the free electrons oscillate out of phase with respect to the driving electric field within this region that following the Drude free electron model.

\subsection{X-ray photoelectron spectroscopy (XPS)}

The $\mathrm{Sb}_{2} \mathrm{Se}_{3}$ is an air sensitive material. The oxide phase of $\mathrm{Sb}_{2} \mathrm{Se}_{3}$ affects the device performance. It is important to investigate the purity of the annealed film because oxygen contamination greatly affect its chemical states which subsequently may be introduced deep trap levels below the conduction band. This introducing trap level could be acted as the recombination centers for the carriers resulting in deterioration of the devices performance. To this point of view, we examined the purity of $\mathrm{Sb}_{2} \mathrm{Se}_{3}$ using powerful depth-profiling $X$-ray photoelectron spectroscopy (XPS). From Fig. 6, $a$ it is seen that the $\mathrm{Sb}^{3 d}$ core level exhibits two chemical states of $\mathrm{Sb}_{2} \mathrm{Se}_{3}$ at $529.34 \mathrm{eV}\left(\mathrm{Sb} 3 d_{5 / 2}\right)$ and $538.73 \mathrm{eV}\left(\mathrm{Sb} 3 d_{3 / 2}\right)$. The spin-orbit splitting is found to be $9.39 \mathrm{eV}$ is an excellent agreement with the report [2]. In Fig. 6, $a$ the deconvolution indicated by $\mathrm{Sb}_{2} \mathrm{Se}_{3}\left(1\right.$ and $\left.1^{\prime}\right), \mathrm{Sb}_{2} \mathrm{O}_{3}\left(2\right.$ and $\left.2^{\prime}\right)$ and an oxygen overlapping peak is (3) [2]. These spectra confirmed that $\mathrm{Sb}_{2} \mathrm{Se}_{3}$ film could be easily oxidized and its chemical state of $\mathrm{Sb}_{2} \mathrm{O}_{3}(532.66 \mathrm{eV})$. Whereas, $\mathrm{Sb} 4 d$ and $\mathrm{Se} 3 d$ core levels also exhibit two chemical states at $33.02 \mathrm{eV}\left(\mathrm{Sb} 4 d_{5 / 2}\right), 34.47 \mathrm{eV}\left(\mathrm{Sb} 4 d_{3 / 2}\right)$ and $54.22 \mathrm{eV}$ $\left(\mathrm{Se} 3 d_{5 / 2}\right), 55.64 \mathrm{eV}\left(\mathrm{Se} 3 d_{3 / 2}\right)$, respectively. The binding energy of all elements are tabulated in Table 3. From Fig. 6, $a$ it can be seen that the O1s peak is disappeared after sputtering of $10.15 \mathrm{~nm}$. The core levels positions are shifted toward the lower binding energy. Both Se3d (Fig. 6, $b^{\prime}$ ) and Sb4d (Fig. 6, $c^{\prime}$ ) core exhibited single peak. Disappearing of this oxygen peak for sputtering of $10.15 \mathrm{~nm}$ indicates that the oxygen layer can form on the surface of $\mathrm{Sb}_{2} \mathrm{Se}_{3}$ rather than deep within the film. Therefore, the thickness of the oxide layer is estimated using equation (4)

$$
I_{\mathrm{O}}=I_{\mathrm{Sb}}\left(1-e^{-\frac{d}{\lambda \cos \theta}}\right) .
$$

Where, $I_{\mathrm{O}}$ and $I_{\mathrm{Sb}}$ are the intensities of the overlapping oxygen and $\mathrm{Sb}$ peak, $\lambda=1.2 \mathrm{~nm}$ is the inelastic mean free path for $\sim 500 \mathrm{eV}$ photoelectron, $\theta=0^{\circ}$ is the polar angle, $d$ is the oxide thickness.
Table 3. Binding energy (eV) of different elements

\begin{tabular}{c|c|c|c|c|c|c}
\hline \multicolumn{3}{c|}{$\mathrm{Sb}$} & \multicolumn{2}{c|}{$\mathrm{Se}$} & $\mathrm{O}$ \\
\hline${\mathrm{Sb} 3 d_{5 / 2}}$ & $\mathrm{Sb3} d_{3 / 2}$ & $\mathrm{Sb}_{4} d_{5 / 2}$ & $\mathrm{Sb}_{4} d_{3 / 2}$ & $\mathrm{Se} 3 d_{5 / 2}$ & $\mathrm{Se} 3 d_{3 / 2}$ & $\mathrm{O} 1 s$ \\
529.34 & 538.73 & 33.02 & 34.47 & 54.22 & 55.64 & 532.66
\end{tabular}

The oxide thickness is found to be $1.15 \mathrm{~nm}$. Thus, the $\mathrm{Sb}_{2} \mathrm{O}_{3}$ chemical state in the $\mathrm{Sb}_{2} \mathrm{Se}_{3}$ may be introduced from the cooling of the evaporation chamber into RT or during the annealing where $\mathrm{O}_{2}$ can immediately react with $\mathrm{Sb}$, due to standard molar reaction enthalpy $(-718 \mathrm{~kJ} / \mathrm{mol})$ and the larger Gibbs free energy $(-605 \mathrm{~kJ} / \mathrm{mol})$ of $\mathrm{Sb}_{2} \mathrm{O}_{3}$ than enthalpy $(-128 \mathrm{~kJ} / \mathrm{mol})$ and Gibbs free energy $(-125 \mathrm{~kJ} / \mathrm{mol})$ of $\mathrm{Sb}_{2} \mathrm{Se}_{3}$ [2].

\section{Conclusions}

The experimental optical properties of $\mathrm{Sb}_{2} \mathrm{Se}_{3}$ thin film deposited by thermal evaporation method are in good agreement with the theoretical results. The theoretical calculations show that $\mathrm{Sb}_{2} \mathrm{Se}_{3}$ is intrinsically an indirect band gap semiconductor which is consistent with the experimental band gap obtained from UV-vis spectroscopy measurement. The basic optical constants (viz., refractive index, extinction coefficient and dielectric constants) of $\mathrm{Sb}_{2} \mathrm{Se}_{3}$ determined by spectroscopy ellipsometry are much closer to theoretical results. However, the large dielectric constants and refractive index values suggest that exciton binding energy in $\mathrm{Sb}_{2} \mathrm{Se}_{3}$ should be relatively small and an antireflective coating is recommended to enhance the light absorption of $\mathrm{Sb}_{2} \mathrm{Se}_{3}$ based thin film solar cells. The absorption coefficient is greater than $105 \mathrm{~cm}^{-1}$ in the visible-ultraviolet region and the obtained band gap is $(0.9-1.5) \mathrm{eV}$. The as-deposited film is amorphous and the annealed film is crystalline in nature. The surface of $\mathrm{Sb}_{2} \mathrm{Se}_{3}$ is oxidized with a thickness of $1.15 \mathrm{~nm}$. These findings suggest that $\mathrm{Sb}_{2} \mathrm{Se}_{3}$ can be produced by thermal evaporation method for solar cell application and to improve the device efficiency the annealing process should be done in an air protective environment.

Competing interests: The authors declare that they have no competing interests.

Acknowledgements: This work was supported by a grant from the Research Grants Council of the Hong Kong, SAR China (Project No. City U 122812).

\section{References}

[1] Y. Zhou, M. Leng, Z. Xia, J. Zhong, H. Song, X. Liu, B. Yang, J. Zhang, J. Chen, K. Zhou, J. Han, Y. Cheng, J. Tang. Adv. Energy Mater., 4, 1301846 (2014).

[2] X. Liu, J. Chen, M. Luo, M. Leng, Z. Xia, Y. Zhou, S. Qin, D.J. Xue, L. Lv, H. Huang, D. Niu, J. Tang. ACS Appl. Mater. Interfaces, 6, 10687 (2014). 
[3] E. Donges, Z. Anorg. Allg. Chem., 263, 280 (1950).

[4] J.J. Liu, J.M. Liu, C.Q. Liu, W.Q. Lu, S.R. Liu, W.C. Su. Int. Geol. Rev., 41, 1042 (1999).

[5] J. Black, E.M. Conwell, L. Seigle, C.W. Spencer. J. Phys. Chem. Sol., 2, 240 (1957).

[6] F.D. Rosi, B. Abeles, R.V. Jensen. J. Phys. Chem. Sol., 10, 191 (1959).

[7] S.G. Jeffrey, E.S. Toberer. Nature Mater., 7, 105 (2008).

[8] P.M. Fourspring, D.M. DePoy, T.D. Rahmlow, J.E. Lazo Wasemand, E.J. Gratrix. Appl. Optic, 45, 1356 (2006).

[9] B. Zhou, J. Zhu. Nanotechnology, 20, 85604 (2009).

[10] J.A. Chang, J.H. Rhee, S.H. Im, Y.H. Lee, H.J. Kim, S.I. Seok, M.K. Nazeeruddin, M. Gratzel. Nano Lett., 10, 2609 (2010).

[11] P. Arun, A.G. Vedeshwar, N.C. Mehra. J. Phys. D: Appl. Phys., 32, 183 (1999).

[12] Y. Zhou, L. Wang, S. Chen, S. Qin, X. Liu, J. Chen, D.J. Xue, M. Luo, Y. Cao, Y. Cheng, E.H. Sargent, J. Tang. Nature Photonics, 9, 409 (2015).

[13] E. Černošková, R. Todorov, Z. Černošek, J. Holubová, L. Beneš. J. Thermal Analysis and Calorimetry, 118, 105 (2014).

[14] D. Dimitov, D. Tzocheva, D. Kovacheva. Thin Sol. Films, 323, 79 (1998).

[15] X. Liu, C. Chen, L. Wang, J. Zhong, M. Luo, J. Chen, D.J. Xue, D. Li, Y. Zhou, J. Tang. Prog. Photovolt.: Res. Appl., 23, 1828 (2015).

[16] M. Luo, M. Leng, X. Liu, J. Chen, C. Chen, S. Qin, J. Tang. Appl. Phys. Lett., 104, 173904 (2014).

[17] W. Wang, M.T. Winkler, O. Gunawan, T. Gokmen, T.K. Todorov, Y. Zhu, D.B. Mitzi. Adv. Energy Mater., 4, 1301465 (2014).

[18] NREL efficiency chart.

[19] M. Gratzel. Nature Mater., 13, 838 (2014).

[20] M.A. Green, A. Ho-Baillie, H.J. Snaith. Nature Photonics, 8, 506 (2014).

[21] C.E. Patrick, F. Giustino. Adv. Funct. Mater., 21, 4663 (2011).

[22] M. Wuttig, N. Yamada. Nature Mater., 6, 824 (2007).

[23] H. Zhang, C.X. Liu, X.L. Qi, X. Dai, Z. Fang, S.C. Zhang. Nature Phys., 5, 438 (2009).

[24] G.J. Snyder, E.S. Toberer. Nature Mater., 7, 105 (2008).

[25] N.W. Tideswell, F.H. Kruse, J.D. McCullough. Acta Crystallogr., 10, 99 (1957).

[26] R.K. Vadapoo, S. Krishnan, H. Yilmaz, C. Marin. Phys. Status Solidi B, 248, 700 (2011).

[27] W. Procarione, C. Wood. Phys. Status Solidi, 42, 871 (1970).

[28] F. Kosek, J. Tulka, L. Sťourac. Czech. J. Phys. B, 28, 325 (1978).

[29] L.R. Gilbert, B. Van Pelt, C. Wood. J. Phys. Chem. Sol., 35, 1629 (1974).

[30] K.A. Chandrasekharan, A.G. Kunjomana. Turk. J. Phys., 33, 1 (2009).

[31] X. Zheng, Y. Xie, L. Zhu, X. Jiang, Y. Jia, W. Song, Y. Sun. Inorg. Chem., 41, 455 (2002).

[32] A.P. Torane, K.Y. Rajpure, C.H. Bhosale. Mater. Chem. Phys., 61, 219 (1999).

[33] K.Y. Rajpure, C.D. Lokhande, C.H. Bhosale. Mater. Res. Bulleten, 34, 1079 (1999).

[34] K.Y. Rajpure, C.D. Lokhande, C.H. Bhosale. Thin Sol. Films, 311, 114 (1997).

[35] Y. Rodriguez-Lazcano, Y. Pena, M.T.S. Nair, P.K. Nair. Thin Sol. Films, 493, 77 (2005).

[36] H.T. El-Shair, A.M. Ibrahim, E. Abd El-Wahabb, M.A. Afify, F. Abd El-Salam. Vacuum, 42, 911 (1991).
[37] E.A. El-Sayad, A.M. Moustafa, S.Y. Marzouk. Physica B (Amsterdam), 404, 1119 (2009).

[38] S. Messina, M.T.S. Nair, P.K. Nair. J. Electrochem. Soc., 156, H327 (2009).

[39] G.Y. Chen, B. Dneg, G.B. Cai, T.K. Zhang, W.F. Dong, W.X. Zhang, A.W. Xu. J. Phys. Chem. C, 112, 672 (2008).

[40] H. Koc, Amirullah M. Mamedov, E. Deligoz, H. Ozisik. Sol. St. Sci., 14, 1211 (2012).

[41] Z. Li, H. Zhu, Y. Guo, X. Niu, X. Chen, C. Zhang, W. Zhang, X. Liang, D. Zhou, J. Chen, Y. Mai. Appl. Phys. Express, 9, 052302 (2016).

[42] Y.C Choi, T.N. Mandal, W.S. Yang, Y.H. Lee, S.H. Im, J.H. Noh, S.I. Seok. Angewandte Chemie, 126, 1353 (2014).

[43] T.T. Ngo, S. Chavhan, I. Kosta, O. Miguel, H.J. Grande, R. Tena-Zaera. ACS Appl. Mater. Interfaces, 6, 2836 (2014).

[44] D.E. Lee, J.Y. Wu, W.Z. Lin, M.W. Leez. J. Electrochem. Soc., 161, H880 (2014).

[45] S.J. Clark et al. First principles methods using CASTEP Zeitschriftfur Kristallographie, 220, 567 (2005).

[46] A.M. Moustafa, E.A. El-Sayed. Egypt. J. Solid., 32, 71 (2009).

[47] M. Masoudi, M. Hashim, H.M. Kamari, M.S. Salit. Modern Appl. Sci., 6, 6 (2012).

[48] Y.X. Zhang, G.H. Li, B. Zhang, L.D. Zhang. Mater. Lett., 58, 2279 (2004).

[49] M. Malligavathya, R.T. Ananth Kumar, Chandasree Das, S. Asokan, D. Pathinettam Padiyan. J. Non-Cryst. Sol., 429, 93 (2015).

[50] B.S. Naidu, M. Pandey, V. Sudarsan, R.K. Vatsa, R. Tewari. Chem. Phys. Lett., 474, 180 (2009).

[51] A.M. Salem, M.S. Selim. J. Phys. D: Appl. Phys., 34, 12 (2001).

[52] M. Kamruzzaman, L. Chaoping, F. Yishu, A.K.M. Faridulislam, J.A. Zapien. RSC Advances, 6, 99282 (2016).

[53] A. Jain, G. Hautier, C. Moore, S.P. Ong, C.C. Fischer, T. Mueller, K.A. Persson, G. Ceder. Computational Mater. Sci., 50, 2295 (2011).

[54] S. Minoura, K. Kodera, T. Maekawa, K. Miyazaki, S. Niki, H. Fujiwara. J. Appl. Phys., 113, 63505 (2013).

Редактор K.V. Emtsev 